\title{
Undergraduate Saudi Nursing Students Attitudes towards Nursing Profession
}

\section{Abbas Al Mutair* and Fatimah Redwan}

Mohammed Al Mana College for Health Sciences, Ministry of Education, Saudi Arabia

*Corresponding author: Abbas Al Mutair, Mohammed Al Mana College for Health Sciences, Ministry of Education, 12445, Al Mubarraz Al Ahsa, East Region 31982, Saudi Arabia, Tel: 00966555877487; E-mail: abbas4080@hotmail.com

Received date: Oct 28, 2015; Accepted date: Jan 07, 2016; Published date: Jan 15, 2016

Copyright: (c) 2016 Abbas Al Mutair, et al. This is an open-access article distributed under the terms of the Creative Commons Attribution License, which permits unrestricted use, distribution, and reproduction in any medium, provided the original author and source are credited.

\begin{abstract}
Aim of the study: To identify the attitudes of undergraduate Saudi nursing students towards studying nursing profession.

Background: Nursing profession is the backbone of the healthcare services and nurses in the workplace should be accountable to deliver high-quality of care. The Saudi Society, cultural forces and values influence nursing profession and its development. Assessment of undergraduate attitudes towards nursing profession is vital as it can help to identify the potential barriers, deficits and challenges to conquer them.
\end{abstract}

Methods: A descriptive cross-sectional survey was administered. The survey design was intended to identify the undergraduate Saudi nursing students' attitudes towards studying nursing profession. Questionnaires were randomly distributed to 250 nursing students. Descriptive statistics were employed to identify the students' attitudes towards the profession.

Results: A total of 141 students completed the survey questionnaires giving a response rate of $56.4 \%$. The participating students $70(52 \%)$ indicated that the most commonly reason to choose studying nursing was their own interest. Most of the students (48.90\%) agreed that their English language proficiency is the hardest in the nursing program. The results showed that students favor to work on direct patient care rather than holding managerial or educational tasks. Generally speaking, the students' families and friends had positive attitudes towards nursing profession.

Conclusion: The nursing students and families in Saudi Arabia had strong positive attitudes towards studying nursing profession. Universities in Saudi Arabia are to increase enrolling students to study nursing and should commit to graduate highly competent nurses to compensate the nursing shortage. Lack of students' awareness of workplace literacy requirements might lead to difficulty in designing appropriate curriculum.

Keywords: Attitudes; Bachelor of nursing; English proficiency; Patient care; Undergraduates; Saudi arabia; Studying nursing

\section{What Does this Paper Contribute to the Wider Global Clinical Community?}

1. The image of nursing in Saudi Arabia has been changed significantly.

2. Holding positive attitudes towards nursing would facilitate the development of the profession.

\section{Introduction}

Florence Nightingale did not only develop the first school of nursing but was also committed to training nurses for the nursing profession and that's why the Florence Nightingale's model of "training" spread quickly throughout the world and successfully improved the quality of nursing services [1]. Currently, nursing education in Saudi Arabia has been given an utmost consideration to cope with the recent requirements of nursing education in the developed countries. This utmost consideration has come from the realization that education for professional nursing is the backbone of the health services and plays a vital role in the promotion of health and quality of life. Consequently, nursing input in health care delivery is important to achieve health for all [2] and in the Saudi society, nursing influences and is influenced by the values and socio-cultural forces.

The Mohammad Al-Mana College for Health Sciences began as an Institute. The institute was up-graded in 2008 to a college, offered the three year-nursing Diploma program parallel to a bachelor in nursing. The composition of the nursing curriculum is influenced by the Ministry of Education, faculty and nursing requirements. Nursing requirements include all courses related to preparing students for the nursing profession and licensure. The final year of the course is an internship period in clinical practice, offering the students the opportunity to consolidate their skills and knowledge. The curriculum for the nursing program is covered over five years which are allocated to lectures, laboratory work and clinical practice and are all delivered through the medium of English language...

The enrollment of female to the nursing profession has been objected by both Saudi parents and students as they were concerned that female and male will work together in a mix working environment 
and that they will be away from home due to the long working hours and shifts duty. The image of nursing in Saudi Arabia has been changing gradually from holding very negative attitudes to positive attitudes towards the profession.

\section{Background}

Saudi Arabia has a long nursing history began 1400 years ago in the time of Prophet Mohammed, PBUHP. Rufaida Al-Asalmya serviced the Muslim casualties during the holy wars. She was allowed to continue her work in times of peace in a tent. The first nursing institute in Saudi Arabia was established in Riyadh City in 1959 [3] The training program was a result of collaboration between the Saudi Arabian Ministry of Health $(\mathrm{MOH})$ and the World Health Organization (WHO). It was one year training course which offered the male graduates license to work as a nurse assistant. In this year (1959), fifteen male students were enrolled in the nursing program that had an elementary preparation (six years of schooling). In 1961, another institute was established in Jeddah City. The two institutes in Riyadh and Jeddah opened the door to Saudi women to enroll into nursing $[3,4]$. The enrollment of female to the institute was objected by both Saudi parents and students as they were concerned that female and male will work together in a mix working environment and that they will be away from home due to the long working hours and shifts duty [5].

The Ministry of Health continued to open new institutes for men and women separately in various cities having a total of 17 female and 16 male institutes by 1990 [3]. In 1992 the Ministry of Health opened the first junior college of nursing in the Kingdom. It was a three years course post high school which licenses the graduates to work as nursing technicians (enrolled nurse or unregistered nurse). For almost 50 years, the $\mathrm{MOH}$ continued to train nursing and hire the graduates to work in the ministry's health facilities. Increasingly, the $\mathrm{MOH}$ for several years operated the two levels of nursing education; nursing institutes and nursing colleges. By 2008, there were four Health Institutes and 33 Health Science Colleges in the country and by June 2011, all other nursing diploma and associate degrees programs were ceased.

The Ministry of Higher Education in 1976 established the first Bachelor of Science in nursing program at King Saud University in Riyadh, in 1977 and 1987 the bachelor program was introduced at King Abdulaziz University in Jeddah and King Faisal University in Dammam respectively. The course duration held in these three universities is five years. Additionally, in 1987 the nursing faculty of King Saud University in Riyadh started to offer the Master of Nursing program. Today there are over fifteen colleges offering BSN Programs in the Kingdom including Mohammed Al Mana College for Health Sciences.

\section{Methods}

\section{Design}

The study employed a survey design using a questionnaire developed for the study. The questionnaire was developed for this study to collect quantitative data; it covered the nursing attitudes towards the nursing profession. The overall sample used was a probability convenience sample to recruit nursing students. The inclusion criteria were that any nursing students from level I
Sophomore Year to Level II Senior Year were eligible to participate in the study.

\section{Ethical consideration}

The approval was sought from Mohammed Al Mana college's Institutional Review Board was secured; the self-administered questionnaire was distributed to the various levels of nursing students. Participants were informed that participation was voluntary and consent was inferred by the submission of the completed questionnaire

\section{Study setting}

Mohammed Al Mana College for Health sciences was the setting of this study. The college is located at Al Khobar city in the eastern province of the Kingdom of Saudi Arabia. It offers bachelor degree in Nursing, Pharmacy and Medical Laboratory Technology. There are a total of 250 students enrolled in the different levels of nursing program.

\section{Data collection}

Data were collected between April and June 2015. Of the 250 questionnaires distributed, 141 were returned (response rate $56.4 \%$ ). The study questionnaire consisted of 13 items which cover the participants' demographics and attitudes. The first part of the questionnaire was to identify the socio-demographic background of the respondents and to obtain information to describe the sample. The attitudes' statements were adapted from a wide range of literature and personal experience.

Content and face validity of the questionnaire were assessed by a panel of five experts. The experts were chosen for their knowledge and experience in academia who were drawn from Mohammed Al Mana college for health sciences in Saudi Arabia. The panel was asked to indicate if each item adequately represented the topic, their responses were then taken into account and the changes were made. Then the questionnaire was trialed on nursing students who were asked to complete the questionnaires in the English language. The students were asked to write their comments to determine whether the items were accessible and clear to understand.

\section{Statistical analysis}

Demographic data and responses to questionnaire items were imported into the statistical package and analyzed. Data were collated via descriptive statistics using IBM-SPSS Version 22. Descriptive statistics including frequency distribution, percentage and mean were computed. The results of the analysis are presented in the following sections.

\section{Results}

Of the 141 respondents, $12(8.6 \%)$ were preparatory year students, $59(42.1 \%)$ were Sophomore, $23(16.4 \%)$ were Junior and $46(32.9 \%)$ were Senior.

\section{Participants' characteristics}

The median age of the participating students was 21 years, female students represented the vast majority of the sample 135 (96.5\%) and 5 (3.5\%) were male nursing students. Of the 141 participating students $43(30.5 \%)$ were married and are a mother of one to two children. The 
Citation: $\quad$ Al Mutair A, Redwan F (2016) Undergraduate Saudi Nursing Students Attitudes towards Nursing Profession. J Nurs Care 5: 329. doi:

Page 3 of 5

participating students' city of residency is displayed in Table 1. The nursing students fathers' level of education was mainly high school 51 (37\%) and university education $43(31.2 \%)$.

\begin{tabular}{|c|c|c|}
\hline \multirow[t]{3}{*}{ Gender } & Male & $5(3.5 \%)$ \\
\hline & Female & $135(96.5 \%)$ \\
\hline & Missing & 1 \\
\hline \multirow[t]{3}{*}{ Students' age } & Minimum age & 18 \\
\hline & Maximum age & 25 \\
\hline & Median (IQR) & $21(1)$ \\
\hline \multirow[t]{5}{*}{ Academic year } & Preparatory year & $12(8.6 \%)$ \\
\hline & Sophomore & $59(42.1 \%)$ \\
\hline & Junior & $23(16.4 \%)$ \\
\hline & Senior & $46(32.9 \%)$ \\
\hline & Missing & 1 \\
\hline \multirow[t]{3}{*}{ Marital status } & Married & $43(30.5 \%)$ \\
\hline & Unmarried & $96(68.8 \%)$ \\
\hline & Missing & 2 \\
\hline \multirow[t]{3}{*}{ Number of children } & $\begin{array}{l}\text { Minimum number of } \\
\text { children }\end{array}$ & 1 \\
\hline & $\begin{array}{l}\text { Maximum number of } \\
\text { children }\end{array}$ & 2 \\
\hline & Median (SD) & $2(0)$ \\
\hline \multirow[t]{5}{*}{ City of residency } & Qatif & $69(68.3 \%)$ \\
\hline & Al Ahsa & $8(7.9 \%)$ \\
\hline & Dammam & $13(12.9 \%)$ \\
\hline & AL Khobar & $11(10.9 \%)$ \\
\hline & Missing & 40 \\
\hline \multirow[t]{6}{*}{$\begin{array}{l}\text { Student's father level of } \\
\text { education }\end{array}$} & Illiterate & $10(7.2 \%)$ \\
\hline & Elementary school & $33(23.9 \%)$ \\
\hline & High school & $51(37 \%)$ \\
\hline & University education & $43(31.2 \%)$ \\
\hline & Post graduate studies & $1(0.7 \%)$ \\
\hline & Missing & 1 \\
\hline
\end{tabular}

Table 1: Participants' demographics characteristics $(\mathrm{n}=141)$.

As shown in Figure 1, the students revealed that the most commonly reason to choose studying nursing was their own interest.
There was also an agreement that students decided to study nursing as it was the only available alternative similarly due to the availability of nursing jobs in the Kingdom. Increasingly, the results showed that only few students' parents had pushed them to study nursing.

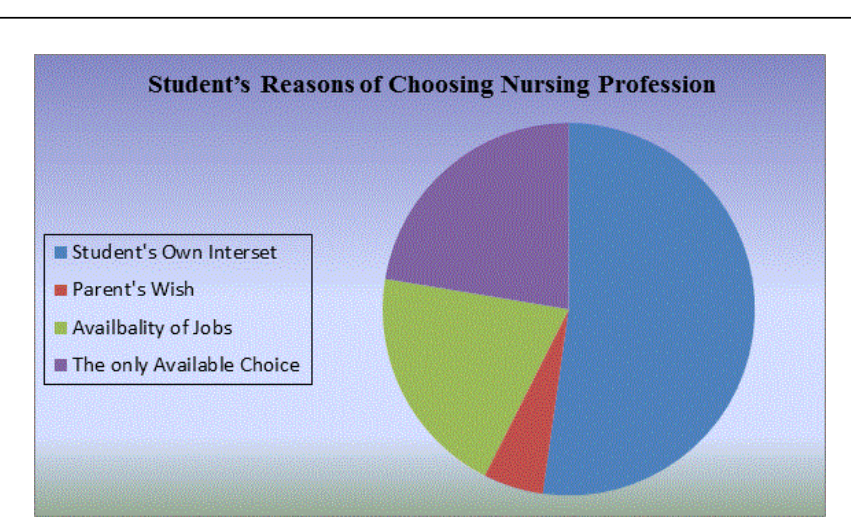

Figure 1: Students reasons of choosing nursing professions.

Students were asked to indicate what hard in studying nursing (Figure 2). Many students (48.90\%) agreed that their English language proficiency is the hardest concern. While approximately $17.30 \%$ identified unclear study plan made studying nursing tough. Clinical part of the nursing curriculum, mixed working environment in the hospitals (male and female) and the unequipped nursing labs at the college were also viewed by some students as making studying nursing hard.

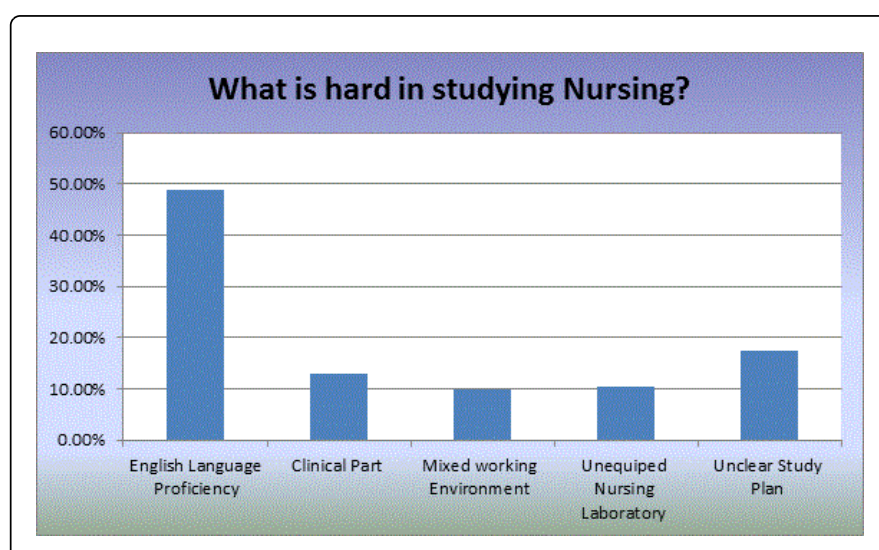

Figure 2: What is hard in studying nursing?

Table 2 presented in the following section provides the participants rating on a 3-point Likert Scale on family and friends attitudes towards studying nursing. As illustrated in Table 2, there was a strong positive response in respect to families' and friends attitudes towards nursing. As can be seen families and friends favored the students to do nursing.

\section{Item}


Page 4 of 5

\begin{tabular}{|l|l|l|l|}
\hline Family attitudes towards studying nursing & $116(85.3 \%)$ & $17(12.5 \%)$ & $3(2.2 \%)$ \\
\hline Friends' attitudes towards studying nursing & $92(66.7 \%)$ & $39(28.3 \%)$ & $7(5.1 \%)$ \\
\hline
\end{tabular}

Table 2: Family's and friend's attitude towards studying nursing profession $(\mathrm{n}=141)$.

The respondents were given the opportunity to indicate their preferred nursing specialty. Medical-Surgical Nursing followed by Pediatric Nursing then Maternity Nursing and Critical Care Nursing were recognized as the most preferred nursing specialty by the students. Whereas, nursing management, Psychiatric Nursing, Nursing Education and Community Nursing were perceived as the least preferred nursing specialty (Figure 3 ).

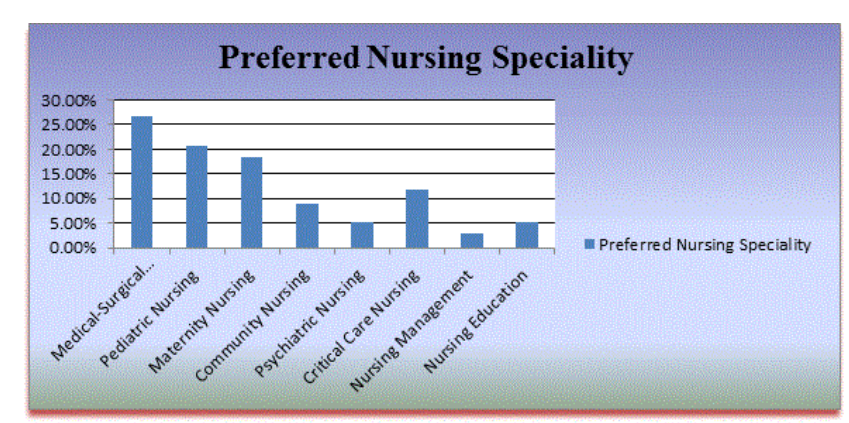

Figure 3: Preferred nursing speciality.

\section{Discussion}

The study explored the undergraduate Saudi nursing students' attitudes towards studying nursing profession. The results of this study provide an interesting picture of how the students', their families and friends valued the nursing profession. Giving that the majority of the nursing students and their families held positive attitudes towards studying nursing, such findings give an indication of nursing acceptance in Saudi Arabia. Despite the fact that female students were the vast majority of students surveyed in the current study 135 (96.5\%), they held positive attitude towards nursing profession. This is different from previous study which reported that enrollment of female to nursing was objected by both parents and students as they were concerned that female will work together with male in a mix working environment [5]. The view of nursing in Saudi Arabia has been dramatically changed due to many reasons including globalization, modernization and Saudisation policy. Like other societies, the Saudi society was influenced by the globalization and modernizations of nursing have played a significant role in lessening the cultural rejection of nursing as profession in Saudi Arabia [5,6]. Women are routinely to be seen working with men in a smoothly manner in the hospitals. Additionally, the government has placed a high priority on implementing of the Saudisation policy which has placed emphasis on increasing the number of Saudi citizens in the workforce [6]. The number of Saudi nurses in the three different health sectors is still limited while expatriates nurses represent more than half of the nursing workforce [7]. This opens a broad opportunity for the Saudi citizens to study nursing in order to replace the expatriate nursing positions. This phenomenon was supported by other finding of the current study which revealed that more than half of the students indicated that choosing to study nursing was the student's own interest. This demonstrates there is a change in the society's view to the nursing profession, contrary to what was common more than 50 years ago. It is believed that the economic and social variables in the Kingdom played an important role in the relative change of how Saudi society look towards nursing profession. For instance, some men who refuse to let their daughter or wife to work in the nursing field found that nursing provides good income and perhaps exceeds their income sometimes which facilitated to accept the profession.

The results of this study raise a number of important issues for nursing education and practice, and identify potential areas for future research. Almost half of the students identified English proficiency as one of the hurdles in studying nursing. The entirely nursing curriculum program is instructed by English language including lectures, laboratory work and clinical practice. There are a number of factors and issues affecting English Language education in Saudi Arabia. In the middle and secondary schools (from the 7th to 12th grade), English is taught four times a week for 45 minutes a day. These English classes are taught by Arab nonnative English speakers and most often are not specialized in teaching English as Foreign Language [8]. Students prior to college enrollment do not have sufficient exposure to the English language and English is not taught intensively to enable them to use it in sophisticated manner later whether in academic or workplace. Cummins in 2010 insisted that students need about seven to ten years of immersion in the target language to achieve academic language [9]. Additionally, at the school level Saudi students consider English as insignificant because it is not used in the students' everyday life and deals with a foreign culture that they have no contact or interaction with [10]. Hence, many objectives of English teaching are not achieved as considerable number of students finishes English courses by memorizing vocabulary, spelling and grammar rules rather than treating it as an important communication medium for their workplaces.

The current study findings showed that clinical nursing including medical-surgical nursing, pediatric and maternity nursing were perceived as the preferred nursing specialties and students would favor to work more in abovementioned specialties. It seems that students favor to work on direct patient care rather than holding managerial or educational tasks. This is anticipated as students at this stage (college stage) strive to draws on the clinical nursing knowledge. Also, students at this stage might do not have a clear complete assumption of what specialty they direct their profession to.

There were limitations relating to the methodology used, selfadministered questionnaire may lead to information bias. In addition, the small sample size of the study cannot represent all nursing students' university in Saudi Arabia. Further studies are needed to identify the major contributory factors influencing the Saudi attitudes towards studying nursing in Saudi Arabia using different study approach to gain in-depth data. 
Citation: $\quad$ Al Mutair A, Redwan F (2016) Undergraduate Saudi Nursing Students Attitudes towards Nursing Profession. J Nurs Care 5: 329. doi: 10.4172/2167-1168.1000329

Page 5 of 5

\section{Conclusion}

The attitude of Saudi nursing students and families tends to be strong positive attitudes towards nursing profession. The students' own interest mainly was the cause behind studying nursing. English was perceived as a barrier which made studying nursing hard. Also, students preferred to work in the clinical areas rather than non-clinical areas.

\section{Relevance to Clinical Practice}

The students and their families had positive attitudes toward nursing profession in Saudi Arabia. This has implications for the university to enroll more students to study nursing and to graduate highly competent students to compensate the nursing shortage in the Kingdom. Also, increase the students' awareness of workplace literacy requirements which will ultimately lead to designing appropriate nursing and English curriculum.

\section{References}

1. Bastable SB (2008) Nurse as educator. Jones and Bartlett Publishers.

2. Wilson $\mathrm{P}$ (2005) The impact of nursing on patient clinical outcomes: Developing quality indicators to improve care.
3. Tumulty G (2001) Professional development of nursing in Saudi Arabia. Se J Nurs Scholarsh 33: 285-290.

4. Miller-Rosser K, Chapman Y, Francis K (2006) Historical, cultural, and contemporary influences on the status of women in nursing in Saudi Arabia. Se Online J Issues Nurs 11: 8.

5. el-Sanabary N (1993) The education and contribution of women health care professionals in Saudi Arabia: the case of nursing. Se Soc Sci Med 37: 1331-1343.

6. Al-Mahmoud S, Mullen P, Spurgeon P (2012) Saudisation of the nursing workforce: Reality and myths about planning Nurse Training in Saudi Arabia. Journal of American Science 8: 369-379

7. Ministry of Health (2011) Health statistical year book (electronic Version) 99-136.

8. Al-Omrani A (2008) Perceptions and attitudes of Saudi EFL and ESL students toward native and non-native English-speaking teachers (Doctoral dissertation). Retrieved from ProQuest Dissertations and Theses database.

9. Cummins J (2000) Language, power, and pedagogy: Bilingual children in the crossfire. Clevedon, England: Multilingual Matters.

10. Almulhim AM (2001) An English language needs assessment of Saudi College of Technology students with respect to a number of business sectors in Saudi Arabia (Doctoral dissertation). Retrieved from ProQuest Dissertations and Theses database. 